\title{
Risky Sexual Behavior and Knowledge of HIV/AIDS Transmission in a Community Sample: Sexual Orientation, Race, and Gender
}

\author{
Dustin K. Shepler \\ Michigan School of Professional Psychology \\ Kevin P. Johnson \\ Michigan School of Professional Psychology \\ Alicia A. Width \\ Michigan School of Professional Psychology
}

\begin{abstract}
New cases of HIV/AIDS are disproportionately diagnosed among men who identify as lesbian, gay, and bisexual and Black. Reasons for this disparity may be related to differences in knowledge of how HIV/AIDS is transmitted and differences in willingness to engage in risky sexual behaviors. In this study, we examined whether differences in knowledge of HIV/AIDS transmission and engagement in risky sexual behaviors differed among men and women; lesbian, gay, and bisexual and heterosexual people; and White and Black people. Findings indicate knowledge of HIV/AIDS transmission was not related to sexual orientation or gender; however, White participants had higher scores on a measure of knowledge of HIV/AIDS transmission than Black participants. While neither gender nor race seemed to be related to differences in engaging in risky sexual behavior, differences in what types of risky sexual behavior people participated in existed based on sexual orientation. Implications for prevention efforts are addressed.
\end{abstract}

Keywords: risky sexual behavior, HIV/AIDS transmission

\section{Introduction}

Sexual minorities and racial minorities have been, and continue to be, disproportionately affected by the HIV/AIDS epidemic (Barskey, 2016; Centers for Disease Control and Prevention [CDC], 2015b). Moreover, men in these communities are especially impacted by HIV/AIDS. This may be because men, in general, tend to engage in more risky sexual behavior than women (Harris, Jenkins, \& Glaser, 2006) regardless of HIV/AIDS status (Cooperman, Arnsten, \& Klein, 2007). One reason people may choose to engage in risky sexual behavior is because they lack the knowledge of how HIV/AIDS is transmitted. In this study, we examine differences in risky sexual behavior based on race, gender, and sexual orientation. We assessed how knowledge of HIV/AIDS transmission may be related to risky sexual behavior. Better understanding of how different groups of people choose to engage in risky sexual behavior and what they know about HIV/AIDS transmission provides a foundation from which prevention efforts can be developed. Importantly, differences between groups may require different prevention strategies. For example, efforts at improving knowledge of AIDS transmission would only be expected to substantially decrease risky sexual behavior for those who 
lack such knowledge and if knowledge of AIDS transmission is related to or affects risky sexual behavior.

\section{Racial Differences in HIV/AIDS Rates}

Several previous studies have documented the disparities in HIV/AIDS diagnosis rates based on race. In 2011, Black people accounted for $47 \%$ of HIV diagnoses, while White people accounted for $28 \%$ of HIV diagnoses among nonincarcerated individuals in the United States (Barskey, 2016). As indicated in the most recent statistics from the CDC, racial disparity in HIV/AIDS diagnosis persists. Specifically, the CDC's 2015 report indicated that while Black people were diagnosed with HIV at a rate of 44.3 per 100,000 people, White people were diagnosed with HIV at a rate of 5.3 per 100,000 people (CDC, 2016b). In 2015, 21.8 per 100,000 Black people had a diagnosis of AIDS while 2.4 per 100,000 White people had a diagnosis of AIDS (CDC, 2016b).

Black people (38.5\%) are more likely to engage in condomless sex than White people (44.7\%; Higgins \& Wang, 2015), but Black people are more likely than White people to report being tested for HIV/AIDS (Ebrahim, Anderson, Weidle, \& Purcell, 2004). This suggests a reactive rather than preventive approach to managing HIV/AIDS may exist within the Black community, a difference that may be due in part to differences in knowledge of AIDS transmission. Swenson et al. (2010) recruited 1,648 Black adolescents to assess their knowledge of HIV, their sexual health-related cognitions (e.g., "If I have vaginal sex in the next 3 months, I intend to use a condom every time"), sexual health behaviors (e.g., sexual intercourse), and sexual health outcomes (e.g., pregnancy, sexually transmitted infection). They found the average score on the Brief HIV Knowledge Questionnaire was 50\%, suggesting that Black adolescents lack adequate knowledge of sexual health may be especially susceptible to engaging in risky sexual behavior (Swenson et al., 2010). This may partially explain the disproportionate HIV diagnosis rate between Black people and White people. If lack of sexual health knowledge underlies racial differences in HIV contraction rates, then efforts to improve education regarding sexual health would be especially important to consider in prevention efforts. Alternatively, it is possible that cultural or attitudinal differences toward HIV contraction may account for discrepancies in HIV contraction rates. In their exploratory study, Bowleg et al. (2011) found that Black heterosexual men feel pressure to engage in sex with multiple women and view condom use as their partners' responsibility, while Arrington-Sanders et al. (2016) indicated that for young Black gay and bisexual men, limited information about sexual health combined with peers who discouraged condom use led to engaging in more risky sexual behavior. Such pressures may place Black men of any sexual orientation at greater risk of contracting HIV/AIDS than other groups.

While sexual scripts may influence risky sexual behavior, knowledge of AIDS transmission may serve as a protective factor. Kiene et al. (2013) found that HIV prevention information worked in conjunction with behavioral skills to reduce HIV transmission for South Africans. Given the importance of knowledge of AIDS transmission in reducing risky sexual behavior, it is important to understand whether differences in knowledge of AIDS transmission exist and, if so, to design interventions that reduce racial disparities in knowledge of AIDS transmission. In this study, we examined whether knowledge of AIDS transmission and risky sexual behavior differed between White and Black people.

\section{Gender Differences in HIV/AIDS Rates}

Gender differences have been reported in HIV contraction rates. Overall, adult and adolescent men accounted for $81 \%$ of new HIV diagnoses in 2014 (CDC, 2015b). While adult and adolescent males 
contracted HIV at a rate of 27.4 out of 100,000 , adult and adolescent females contracted HIV at a rate of 6.1 out of 100,000 people. The same reactive approach to managing the threat of HIV/AIDS seems to persist among men more than among women. Milligan, Cuneo, Rutstein, and Hicks (2014) found that men more frequently participated in HIV/AIDS testing than women, yet they also engaged in more risky sexual behavior than women (Harris et al., 2006). Research has suggested that based on masculine gender norms, men are more likely to have more sexual partners and report less frequent condom use than women, behaviors which increase the likelihood of contracting/transmitting HIV/AIDS (Lefkowitz, Shearer, Gillen, \& Espinosa-Hernandez, 2014).

Although there is a stark difference in HIV diagnosis rates between men and women, minimal examination of possible differences in knowledge of AIDS transmission has taken place. The limited extant research suggests that gender differences in knowledge of AIDS transmission do not exist. For example, Mahat, Scoloveno, and Scoloveno (2016) found that men and women (all of whom were parents) were similarly knowledgeable regarding transmission of HIV. Nonetheless, Kiene et al. (2013) found that gender differences exist in how knowledge of AIDS transmission is linked to risky sexual behavior, and the World Health Organization (WHO) issued a review paper discussing ways gender should be integrated into HIV/AIDS programs (WHO, 2003). In its review, the WHO emphasized how programs are more effective when gender issues and difference are acknowledged when educating the public on HIV/AIDS (e.g., adequate condom usage knowledge for women, perinatal knowledge of AIDS transmission for men; WHO, 2003). Researchers have studied the role of gender in knowledge of AIDS transmission in other countries (e.g., Bandali, 2011; Li et al., 2004), yet similar research seems to be lacking in the United States. As previously noted, determining whether group differences exist in variables such as knowledge of HIV transmission allows for more targeted (and hopefully effective) prevention efforts. In this study, we investigated whether genderbased differences in knowledge of AIDS transmission and risky sexual behavior were evident. By further promoting discussion and clarifying the role of gender in knowledge of AIDS transmission and risky sexual behavior, development of intervention efforts can be improved.

\section{Sexual Orientation Differences}

Despite the fact that around $90 \%$ of people identify as heterosexual, heterosexuals continue to account for only 30\% of new HIV diagnoses (Beck et al., 2012). This disparity is not restricted to age; lesbian, gay, and bisexual (LGB) boys and girls appear to be at higher risk of contracting HIV than their heterosexual or mostly heterosexual peers (Saewyc et al., 2006).

Much of the research regarding differences in sexual orientation and HIV/AIDS diagnosis has focused on men; however, sexual minority women do not appear to be at reduced risk of contracting HIV/AIDS compared to heterosexual women (Goodenow, Szalacha, Robin, \& Westheimer, 2008; Moore et al., 1996). One study (Goodenow et al., 2008) suggested that sexual minority women may be at equal or even increased risk of contracting HIV/AIDS compared to heterosexual women. Women whom claimed sexual minority identities more often engaged in intravenous drug use than heterosexual women. Subsequently, while the cause of the increased risk for contracting HIV/AIDS was not directly related to sexual behavior, sexual minority women still had an increased probability of contracting HIV/AIDS (Goodenow et al., 2008). No research focused exclusively on women's knowledge of AIDS transmission could be located.

In $2010,61 \%$ of new HIV cases were contracted by men who identified as gay, bisexual, or men who have sex with men (MSM; Prejean et al., 2011). According to the CDC (2016b), 81\% of the youth newly diagnosed with HIV in 2015 identified as being gay or bisexual. One possibility for the disproportionate infection rates may be due to engaging in condomless sex. Despite having 
knowledge of current HIV status, MSM did not like using condoms (65.5\%) and most would rather avoid using condoms if at all possible (70.6\%; Klein \& Kaplan, 2012). Although MSM report less interest in condom use, the preference for condomless sex is not specific to MSM (Brooks, Lee, Newman, \& Leibowitz, 2008). Higgins and Wang (2015) reported that 15- to 24-year-old men and women's "pleasure-related attitudes were more strongly associated with lack of condom use than all sociodemographic or sexual history factors" (p. 1329). Dislike of condoms and formation of sexual habits may lead individuals to ignore known risks when making decisions about sexual behaviors (Klein \& Kaplan, 2012; Ronis, Yates, \& Kirscht, 1989). Therefore, condom use alone is unlikely to explain disproportionate transmission rates among those of differing sexual orientations; other factors, such as community factors, must also be considered (Arrington-Sanders et al., 2016).

MSM have reported engaging in risky sexual behavior at greater frequency than heterosexual men and women (Brooks et al., 2008). Not only have MSM reported less consistent condom use than heterosexual men and women, they have also reported having more sexual partners than heterosexual men and women (Brooks et al., 2008). It appears probable that sexual minority men choose to engage in risky sexual behavior more often than others, which may partially explain differences in HIV transmission. However, whether the decision to engage in risky sexual behavior is dependent on knowledge of AIDS transmission is worth further consideration. Some researchers (Benotsch, Kalichman, \& Cage, 2002; Pleak \& Meyer-Bahlburg, 1990) have found that knowledge of AIDS transmission correlated with safer sex practices among men. More research pertaining to knowledge of AIDS transmission and sexual orientation may help develop effective preventive measures in education.

\section{Knowledge of HIV/AIDS Transmission}

The clear differences observed in HIV/AIDS transmission rates may be related to decisions to engage in risky sexual behavior as well as differences in knowledge of AIDS transmission. Sexual education appears to be somewhat effective in decreasing risky sexual behavior (e.g., Kirby, Laris, \& Rolleri, 2007); however, results are inconsistent as some researchers have reported contradictory findings (e.g., Klein \& Kaplan, 2012). A decline in knowledge of AIDS transmission may also contribute to a perception of low risk of acquiring HIV/AIDS in youth (CDC, 2015a). There is also some indication that accurate understanding of HIV/AIDS transmission and willingness to engage in risky sexual behavior are associated with race (Pflieger, Cook, Niccolai, \& Connell, 2013), gender (Cooperman et al., 2007), and sexual orientation (Maksut, Eaton, Siembida, Driffin, \& Baldwin, 2016). For example, Beck et al. (2012) found that for low-income heterosexual adults, those who lacked knowledge of their HIV/AIDS status and who were younger (18-29 years old) were more likely to hold false beliefs about HIV/AIDS transmission than those who knew their HIV/AIDS status and were older (30-50 years old). Being concerned about HIV/AIDS has been linked to holding accurate knowledge of how HIV/AIDS is transmitted and positive behaviors such as discussing HIV/AIDS with others and "taking precautions to protect oneself against the disease" (Brown \& Bocarnea, 1998, p. 311). There have also been movements toward gender-sensitive education (WHO, 2003) and sexual orientationinformed HIV/AIDS prevention (Ybarra et al., 2016); however, outcome data regarding the effectiveness of these targeted efforts is limited. Through this study, we hoped to better understand potential underlying differences in knowledge of AIDS transmission and risky sexual behavior based on race, gender, and sexual orientation in order to provide direction for prevention efforts.

\section{Current Study}

In this study, we examine how race, gender, and sexual orientation are related to knowledge of AIDS transmission and risky sexual behavior. We hypothesized that differences in risky sexual behavior 
based on race, gender, and sexual orientation would be observed. Specifically, we expected to find that, consistent with past research, Black people would report engaging in more risky sexual behavior than White people (e.g., Arrington-Sanders et al., 2016), men would report engaging in more risky sexual behavior than women (e.g., Harris et al., 2006), and LGB people would report engaging in more risky sexual behavior than heterosexual people (e.g., Klein \& Kaplan, 2012). We suspected that, if these hypotheses were supported, that corresponding differences in knowledge of AIDS transmission would be observed and that knowledge of AIDS transmission would be negatively correlated with risky sexual behavior.

\section{Method}

\section{Participants}

A total of 328 respondents who met the inclusion criteria completed a survey composed of demographic items, a measure of knowledge of AIDS transmission, and a measure of sexual risk taking behaviors. Men $(n=154)$ and women $(n=174)$ ages $18-85(M=32.35, S D=13.47)$ were recruited at an urban lesbian, gay, bisexual, and transgender (LGBT) pride festival in the summer of 2015 for the completion of this study. They identified as either White $(n=255)$ or Black $(n=73)$, and as gay $(n=119)$, lesbian $(n=74)$, bisexual $(n=59)$, or heterosexual $(n=76)$. One hundred eighty-five participants reported being in a romantic relationship at the time of participation. Participants noted their highest level of education as some high school $(n=4)$, high school degree or GED $(n=39)$, some college $(n=101)$, trade school $(n=10)$, associate's degree $(n=33)$, bachelor's degree $(n=78)$, or graduate degree or more $(n=63)$. While most $(n=298)$ participants reported that they were HIV/AIDS negative, 22 reported not knowing their HIV/AIDS status and eight reported having HIV or AIDS.

\section{Instruments}

\section{Sexual Risk Survey}

Risky sexual behavior was assessed using the Sexual Risk Survey (SRS) by Turchik and Garske (2009). The SRS is a 23 -item questionnaire that assesses a broad range of sexual behaviors. Participants are asked about engagement in a variety of sexual behaviors (e.g., vaginal intercourse, anal intercourse, sex with uncommitted partners, etc.). In addition to a total scale score $(M=74.4$, $S D=88.5, \alpha=.77)$, five subscale scores can be calculated: sexual risk taking with uncommitted partners $(M=17.5, S D=31.0, \alpha=.77)$, risky sex acts $(M=36.5, S D=52.4, \alpha=.63)$, impulsive sexual behaviors $(M=8.1, S D=13.7$, alpha $=.54)$, intent to engage in risky sexual behavior $(M=$ 1.7, $S D=5.6, \alpha=.89)$, and risky anal sex acts $(M=8.6, S D=21.1, \alpha=.57)$. Each of the subscales was significantly correlated with the other subscales (see Table 1).

\section{AIDS Concern, Beliefs, and Communication Behavior Inventory}

Knowledge of AIDS transmission was assessed using the Beliefs subscale of the AIDS Concern, Beliefs, and Communication Behavior Inventory. The AIDS Concern, Beliefs, and Communication Behavior Inventory (Brown, 1991) is a 23-item, three-factor standardized scale that measures concern, beliefs, and amount of discussion with others regarding AIDS. The Beliefs subscale is composed of 14 items that assess the veracity of beliefs about how AIDS is transmitted; hence, it actually assesses knowledge of AIDS transmission rather than a subjective belief. The scale was originally published in 1991, and since that time there have been numerous advances in medical research and treatment that have led to new understanding of HIV/AIDS. Subsequently, three items 
were recoded to reflect current scientific understanding of HIV/AIDS. ${ }^{1}$ In this study, the Beliefs subscale had a mean score of $10.66(S D=2.30)$ and a Cronbach's alpha score of .65 .

\section{Procedure}

After obtaining Institutional Review Board approval, participants were approached by volunteers at an urban LGBT pride festival in the Midwestern United States and invited to participate in a survey. After attesting that they were at least 18 years old, participants were offered a seat in a designated area and provided with a clipboard and pen to complete the survey. Relevant informed consent information (e.g., participants' rights and Institutional Review Board contact information) was provided as a cover page on each survey. Those who opted to complete the survey remained anonymous and generally took about $10 \mathrm{~min}$ to complete their participation.

\section{Results}

A preliminary Pearson bivariate correlation analysis was conducted to examine how various types of risky sexual behavior were related to each other and to other variables, such as knowledge of AIDS transmission. All of the subscales that make up the SRS were positively correlated with one another (see Table 1), indicating that those who engage in one type of risky sexual behavior were more likely to engage in other types of risky sexual behavior. Knowledge of AIDS transmission was positively correlated with age $(r=.190, p<.001)$ and education level $(r=.325, p<.001)$, indicating that those with more knowledge of AIDS transmission tended to have higher levels of education. Age was also positively correlated with education level $(r=.355, p<.001)$. Unexpectedly, there was no correlation between any of the risky sexual behavior subscales and knowledge of AIDS transmission. Separate analysis based on race and gender indicated that this was true for both Black and White participants and for men and women. Only education and age were related to knowledge of AIDS transmission.

\footnotetext{
${ }^{1}$ Item 4, which read "Everyone who develops AIDS will eventually die as a result of it (if no other tragedy takes that person's life)" was considered to have a correct answer of "false." This is consistent with Goforth, who noted that while AIDS is not curable, "for most patients today, it's a chronic disease, much like diabetes or heart disease" (Young, 2013, para. 11); Montaner et al. (2014), who reported that expansion of highly active antiretroviral therapy between 1996 and 2012 "was associated with a sustained and profound population-level decrease in morbidity, mortality and HIV transmission" (p. 1); and Watson (2012), who stated, "AIDS is no longer an automatic death sentence" (para. 18) due to advances in treatment. Item 5, which read, "Everyone who has the AIDS virus will develop AIDS," was considered to have a correct response of "false." Various reports (e.g., Roehr, 2009; Slack, 2009) have discussed "elite controllers," those who have contracted the HIV virus, but appear to be immune to developing AIDS. Item 13, which read, "A spermicidal gel or product is effective in killing any AIDS virus that may be present from either partner during sexual intercourse," was considered to be false, as meta-analytic findings have suggested that the use of spermicidal gel is no more effective for destroying HIV (or several other sexually transmitted infections) than placebos or no treatment at all (Wilkinson, Tholandi, Ramjee, \& Rutherford, 2002).
} 
Table 1: Correlation Table for Knowledge of AIDS Transmission, Risky Sexual Behavior, Age, and Education

\begin{tabular}{|c|c|c|c|c|c|c|c|}
\hline & 2 & 3 & 4 & 5 & 6 & 7 & 8 \\
\hline $\begin{array}{l}\text { 1. Knowledge of } \\
\text { AIDS } \\
\text { transmission }\end{array}$ & .026 & .099 & .025 & .045 & .057 & $.190^{* *}$ & $.325^{* *}$ \\
\hline $\begin{array}{l}\text { 2. Sexual risk } \\
\text { taking with } \\
\text { uncommitted } \\
\text { partners }\end{array}$ & & $.299 * *$ & $.400 * *$ & $.505^{* *}$ & $.318^{* *}$ & .005 & -.025 \\
\hline $\begin{array}{l}\text { 3. Risky sexual } \\
\text { acts }\end{array}$ & & & $.179^{* *}$ & $.153^{* *}$ & $.285^{* *}$ & -.060 & -.015 \\
\hline $\begin{array}{l}\text { 4. Impulsive } \\
\text { sexual } \\
\text { behaviors }\end{array}$ & & & & $.597^{* *}$ & $.114^{*}$ & -.014 & -.042 \\
\hline $\begin{array}{l}\text { 5. Intent to } \\
\text { engage in risky } \\
\text { sexual } \\
\text { behaviors }\end{array}$ & & & & & $.170 * *$ & .057 & -.072 \\
\hline $\begin{array}{l}\text { 6. Risky anal sex } \\
\text { acts }\end{array}$ & & & & & & -.050 & -.002 \\
\hline 7. Age & & & & & & & $.355^{* *}$ \\
\hline 8. Education & & & & & & & \\
\hline
\end{tabular}

To examine whether differences in types of risky sexual behavior (i.e., sexual risk taking with uncommitted partners, risky sex acts, impulsive behaviors, intent to engage in risky sexual behaviors, and risky anal sex acts) existed based on race (i.e., White and Black), gender (i.e., men and women), and sexual orientation (lesbian, gay, bisexual, and heterosexual), a multivariate analysis of variance was conducted. Because cell sample sizes were unequal and the assumption of homogeneity of variance was violated (Box's $M=826.86, p \leq .000$ ), Pillai's Trace was used as the criterion as recommended by Tabachnick and Fidell (2001). While no main effect was observed for race or gender, a main effect for sexual orientation was observed: Pillai's trace $=.104, F(15,771)=$ $1.84, p=.026, \mathrm{n}^{2}=.035$ (see Table 2 ). 
Table 2: Multivariate Test Results for Race, Gender, Sexual Orientation, and Risky Sexual Behavior

\begin{tabular}{lcccccc}
\hline Effect or Interaction & Pillai's Trace & $F$ & Hypo $d f$ & $d f$ & $p$ & $\eta^{2}{ }^{2}$ \\
\hline Race & .032 & 1.71 & 5 & 255 & .133 & .032 \\
Gender & .019 & .997 & 5 & 255 & .420 & .019 \\
Sexual orientation & .104 & 1.84 & 15 & 771 & $.026^{*}$ & .035 \\
Gender $\times$ Sex Orientation & .010 & .506 & 5 & 255 & .772 & .010 \\
Gender $\times$ Race & .022 & 1.13 & 5 & 255 & .345 & .022 \\
$\begin{array}{l}\text { Sexual Orientation } \times \\
\text { Race }\end{array}$ & .042 & .735 & 15 & 771 & .749 & .014 \\
\hline
\end{tabular}

Note. $N=270 . \alpha=.05$. Hypo $=$ hypothesis.

To identify the underlying cause for the observed main effect, a discriminant function analysis was conducted. Consistent with Tabachnick and Fidell (2001), a minimum cut off value of 0.32 was used to determine whether a dependent variable varied in an important way between those of differing sexual orientations. Only the first discriminant function (way of grouping or splitting variables) was significant, Wilks $\lambda=0.747, p \leq .000, d f=25$, and explained $81.9 \%$ of the variance with a canonical correlation of 0.457 . The structure matrix indicated that risky sex acts (structure value $=-.597$ ) and risky anal sex acts (structure value $=.426$ ) were both correlated with the discriminant function. This indicates that important differences in these two domains exist among those of different sexual orientations.

Consistent with discriminant function analysis results, post-hoc pair-wise comparison analysis revealed that there were statistically significant differences on risky sexual acts between gay ( $M=$ 19.77, $S D=25.14)$ and heterosexual $(M=61.93, S D=85.93)$ individuals $(p \leq .000)$ and lesbian $(M=$ 28.86, $S D=39.43)$ and heterosexual individuals $(p \leq .002)$. Items measured on the Risky Sexual Acts scale include behaviors such as vaginal sex, cunnilingus, or fellatio without a condom or other protection or while under the influence of substances. A statistically significant difference also existed for risky anal sex acts between gay $(M=16.58, S D=27.98)$ and lesbian $(M=5.40, S D=$ $22.01)$ individuals $(p \leq .010)$, gay and bisexual $(M=5.11, S D=10.54)$ individuals $(p=.013)$, and gay and heterosexual $(M=5.71, S D=17.15)$ individuals $(p=.016)$. Overall, it appears that while heterosexuals engage in more risky sexual acts in general, gay men engage in more risky anal sex acts than those who identify as heterosexual or lesbian. Results may reflect preferences in types of sexual activity related to sexual orientation rather than actual differences in engaging in risky sexual behavior.

Analysis was conducted to examine if knowledge of AIDS transmission differed by race, gender, and sexual orientation. While no significant differences in knowledge of AIDS transmission were observed based on gender and sexual orientation (see Table 3), results indicated that there was a statistically significant main effect between race and knowledge of AIDS transmission, $F(1,316)=$ $7.296, p=.007, \eta^{2}=.023$. A Tukey's post-hoc analysis revealed that White individuals $(M=10.89, S D$ $=2.43)$ had more knowledge of AIDS transmission than Black individuals $(M=10.46, S D=2.17)$. 
Table 3: Analysis of Variance Results for Race, Sexual Orientation, and Gender on Knowledge of AIDS

\begin{tabular}{lcccccc}
\hline Effect or Interaction & $\begin{array}{c}\text { Sum of } \\
\text { Squares }\end{array}$ & $d f$ & $\begin{array}{c}\text { Mean } \\
\text { Square }\end{array}$ & $F$ & $p$ & $\eta^{2}{ }^{2}$ \\
\hline Race & 36.79 & 1 & 36.79 & 7.30 & .007 & .023 \\
Gender & .000 & 1 & .000 & .000 & .994 & .000 \\
Sexual Orientation & 2.54 & 3 & .845 & .168 & .918 & .002 \\
Race $\times$ Sex Orientation & 5.260 & 3 & 1.753 & .348 & .791 & .003 \\
Race $\times$ Gender & .249 & 1 & .249 & .049 & .824 & .000 \\
Sexual Orientation $\times$ & .068 & 1 & .068 & .014 & .907 & .000 \\
Gender & & & & & & .000 \\
Race $\times$ Sexual & .080 & 1 & .080 & .016 & .900 & \\
Orientation*Gender & & & & & &
\end{tabular}

\section{Discussion}

Researchers have reported disparities in HIV transmission rates. Findings have indicated that Black people, LGB people, and men have higher rates of contracting HIV than White people, heterosexual people, and women (e.g., Barskey, 2016; CDC, 2016b; Linley, Prejean, An, Chen, \& Hal, 2012). Some have reported that the noted disparities may reflect differences in sexual risk taking and knowledge of AIDS transmission (Arrington-Sanders et al., 2016). To further examine this possibility, data were collected from an urban LGBT pride event, and knowledge of AIDS transmission and risky sexual behavior were assessed among event attendees.

\section{Knowledge of AIDS Transmission}

As stated previously, Black individuals are disproportionately diagnosed with HIV/AIDS compared to White individuals (CDC, 2015b). Some researchers have suggested that Black individuals are at a higher risk of diagnosis due to disparities in health care access (Barskey, 2016) and utilization (Milligan et al., 2014). While no differences in knowledge of AIDS transmission were found based on gender or sexual identity in our study, participants who identified as White scored higher on a measure of knowledge of AIDS transmission than those who identified as Black. Our findings suggest that, in addition to noted differences in health care access and utilization, those who identify as Black also appear to have less knowledge of AIDS transmission. However, knowledge of AIDS transmission did not correlate to any of the five risky sexual behavior factors among Black participants in this study. Our findings suggest that it may be useful to increase educational efforts to increase knowledge of AIDS transmission in Black communities. More educational and healthcare access services are needed to help reduce HIV/AIDS transmission.

No between group differences in knowledge of AIDS transmission were observed between men and women or among those of differing sexual orientations. Our findings suggest that disparities in HIV/AIDS transmission rates based on sexual identity and gender (Beck et al., 2012; Goodenow et 
al., 2008; Moore et al., 1996; Prejean et al., 2011) are not due to differences in knowledge of AIDS transmission. Specifically, despite similar levels of knowledge of AIDS transmission, gay men reported more risky anal sex acts than heterosexual people and heterosexual people reported engaging in higher rates of other risky sexual behaviors (e.g., vaginal or oral sex without a condom or while under the influence of substances) than lesbian and gay people.

While not the primary focus of this study, it is noteworthy that age appears to be correlated with knowledge of AIDS transmission, yet age did not correlate to risky sexual behavior. Our findings are inconsistent with the CDC's observation that "People aged 50 and older have many of the same HIV risk factors as younger people, but may be less aware of their risk" (CDC, 2016a). Indeed, findings from this study and others (e.g., Beck et al., 2012) suggest that older individuals may be more knowledgeable about HIV/AIDS transmission factors than younger individuals. Despite having more knowledge, older individuals do not have lower diagnosis rates of HIV/AIDS (CDC, 2015a). It is possible that, like younger individuals who see themselves as immune to getting HIV (Shiferaw et al., 2014), older individuals also see themselves as not at risk for contracting HIV/AIDS despite knowing how HIV/AIDS is transmitted. Future research should focus on achieving a better understanding of whether older individuals do, in fact, feel that they are invulnerable to HIV/AIDS.

Generally, past research has found that knowledge of AIDS transmission alone is not sufficient to increase safer sex practices (Davis, Hughes, Sloan, Tang, \& MacMaster, 2009; Ronis et al., 1989; Sharma, Sullivan, \& Stephenson, 2017). Others have indicated that certain cognitive and social skills may be necessary when making decisions regarding ways to engage in safer sex (Schaalma, Abraham, Gillmore, \& Kok, 2004). Considering that knowledge of AIDS transmission does not seem to relate to risky sexual behavior, increasing knowledge of AIDS transmission alone does not seem to be a promising intervention strategy. Instead, changing attitudes toward engaging in safer sexual behaviors and improving sexual communication and decision making skills may be more effective in reducing risky sexual behavior and, subsequently, the transmission of HIV/AIDS.

Understanding underlying reasons for disproportionate HIV diagnosis is important in tailoring prevention programs aimed at decreasing HIV transmission. Results indicate that knowledge of AIDS transmission is not related to engaging in risky sexual behavior. This is concerning because AIDS education programs, even when effective in teaching how individuals can protect themselves, may not be likely to cause people to engage in safer sexual practices. One possibility for this finding is that other variables such as communication difficulties and embarrassment related to discussing sexual safety may inhibit even knowledgeable individuals from discussing and practicing safer sexual practices (Hines, 1995, Moore \& Halford, 1996). Future research may clarify whether discomfort or embarrassment in discussing safe sex and condom use is related to engaging in risky sexual behavior.

\section{Risky Sexual Behavior}

Compared to lesbian and gay (but not bisexual) people, heterosexual participants reported more instances of vaginal sex, cunnilingus, fellatio without a condom or other protection, and sex while under the influence of substances. These results differ from previous findings that reported LGB individuals engage in more risky sexual behavior than their heterosexual counterparts (e.g., Brooks et al., 2008; Klein \& Kaplan, 2012). It is understandable that some of the constructs that make up the Risky Sex Acts subscale (the scale that measures the noted sexual behaviors) would be reported in higher frequency for one group over the other. For example, heterosexual individuals intuitively would report having more vaginal intercourse than gay men. The difference in reported vaginal intercourse between lesbian and heterosexual participants is more difficult to understand. While it is 
possible that lesbian women simply do not label sexual activity as "vaginal intercourse" due to traditional conceptualization of intercourse involving penile penetration, we cannot definitively offer an explanation for the observed difference at this time. We also found that gay men reported higher rates of engaging in risky anal sex acts than lesbian, bisexual, and heterosexual individuals. This included engaging in behaviors such as condomless anal sex, unprotected anal penetration, and analingus without protection more than the lesbian, bisexual, and heterosexual participants. While not all gay men engage in anal sex, it is again intuitive that gay men more frequently engage in anal sex than lesbians. Except for those post hoc comparisons that have been discussed, differences based on sexual orientation were not observed. This indicates that as a group, bisexual people do not differ significantly from those of other sexual orientations in terms of a range of risky sexual behaviors. Subsequently, our findings seem to suggest that those of different sexual orientations sometimes engage in different types of risky sexual behavior rather than actually differing in overall frequency of risky sexual behavior.

These findings are inconsistent with previous research indicating that sexual minority individuals engage in more risky sexual behavior than heterosexual individuals (Brooks et al., 2008). We suspect that this difference may be due to three factors; two of which have to do with sampling. First, while Brooks et al. (2008) used population-based survey data collected between 1997 and 2003 in Los Angeles County, California, we collected data from a convenience sample at an urban pride event in 2015. Discrepancy in results may reflect actual changes that occurred over the decade between data collections. Alternatively, it is possible that individuals (both LGB and heterosexual) who attend pride events differ from the broader population in risky sexual behavior and sexual health knowledge. Second, the specific type of survey method may have impacted results. While Brooks et al. used a telephone survey, we used a written survey. It is unknown whether participants may be more or less likely to report engaging in certain behaviors in spoken versus written response.

A third possibility is that previous studies have defined risky sexual behavior in a manner that may bias results. Considering that those of different sexual identities reported engaging in different risky sexual behavior at different rates, types of risky sexual behavior sampled would likely have an impact on results. For example, results would likely differ depending on whether the risky sexual behavior construct were defined with more attention given to anal intercourse versus vaginal intercourse. Regardless of the underlying reason for the noted discrepancy, future research is needed to clarify whether or not differences in risky sexual behavior actually exist between LGB and heterosexual people. Clarifying this relationship would be an important first step in understanding whether risky sexual behavior or other factors actually account for differences in HIV transmission rates.

\section{Limitations}

A key limitation in our study is related to representativeness of our sample population. Past researchers have questioned how representative LGB pride event attendees are of the broader LGB population (Bailey et al., 1999), which is where our data were collected. It is possible that the probable homogeneity of the sample resulted in restriction of range on the risky sexual behavior subscales and the Beliefs subscale, thereby attenuating the correlation between the dependent variables. Our sample also underrepresented individuals with less education (i.e., who had not completed high school) and overrepresented those with advanced education. While not systematically assessed, we also assume most participants were from the geographical area surrounding the pride event location. Subsequently, results may not generalize to other regions of the United States, such as Los Angeles, where HIV education efforts have historically targeted the LGB community (Brooks et al., 2008). Another limitation relates to how the modified knowledge of AIDS transmission scale 
was not factor analyzed. Therefore, updating the scale to reflect current research may have changed the validity of the scale in some unidentified manner. Despite these concerns, there is reason to take the results from this study seriously.

First, unlike much published research on LGB topics, our sample was composed of a diverse group of individuals that allowed for comparisons based on gender, race, and sexual orientation. This corrects an often cited fault in LGB scholarship wherein LGB individuals have been treated as one monolithic group rather than recognized as subgroups within the sexual minority community. Another strength of this work is that rather than treating risky sexual behavior as a single construct, we selected an instrument that allowed for a more nuanced understanding of various aspects of risky sexual behavior. Use of the SRS (Turchik \& Garske, 2009) resulted in recognition that different groups engaged in certain risky sexual behavior at higher rates than others.

\section{Conclusion}

Three main findings were apparent from this study. First, higher levels of knowledge of AIDS transmission were reported by White than Black people and knowledge of AIDS transmission was positively related to age. Second, different types of risky sexual behavior were more frequently endorsed by those of different sexual orientations. Third, knowledge of AIDS transmission was not related to risky sexual behavior. These findings have implications for prevention efforts aimed at addressing HIV/AIDS transmission.

Research has previously shown success addressing HIV/AIDS education and engagement in risky sexual behavior according to race (Pflieger et al., 2013), gender (Cooperman et al., 2007), and sexual orientation (Maksut et al., 2016). This study found that those who identified as White had more knowledge of AIDS transmission compared to those who identified as Black. However, knowledge of AIDS transmission does not appear to be related to risky sexual behavior. Subsequently, increasing educational efforts may not prove as valuable as increasing other skills, such as comfort in talking about safer sex for both Black and White people. Alternatively, education efforts may need to be more tailored to individuals based on racial, sexual orientation, and gender differences. For example, broad education efforts may focus on condomless vaginal intercourse and exclude risk associated with condomless anal intercourse. Modifying educational efforts to be sensitive to preferred types of sexual behavior may be important in helping individuals translate knowledge of AIDS transmission to safer sex practices.

\section{References}

Arrington-Sanders, R., Morgan, A., Oidtman, J., Gomez, M. C., Ogunbajo, A., Trent, M., \& Fortenberry, J. D. (2016). Context of first same-sex condom use and nonuse in young Black gay and bisexual males. Journal of Research on Adolescence, 26, 1009-1021. doi:10.1111/jora.12255

Bailey, J. M., Pillard, R. C., Dawood, K., Miller, M. B., Farrer, L. A., Trivedi, S., \& Murphy, R. L. (1999). A family history study of male sexual orientation using three independent samples. Behavior Genetics, 29, 79-86. doi 10.1023/A:1021652204405

Bandali, S. (2011). Norms and practices within marriage which shape gender roles, HIV/AIDS risk and risk reduction strategies in Cabo Delgado, Mozambique. AIDS Care, 23, 1171-1176. doi:10.1080/09540121.2011.554529 
Barskey, A. L. (2016). Patterns and trends of newly diagnosed HIV infections among adults and adolescents in correctional and noncorrectional facilities, United States, 2008-2011. American Journal of Public Health, 106, 103-109. doi:10.2105/AJPH.2015.302868

Beck, D. W., Lalota, M., Metsch, L. R., Cardenas, G. A., Gorrest, D. W., Lieb, S., \& Liberti, T. M. (2012). HIV prevention and transmission myths among heterosexually active adults in lowincome areas of South Florida. AIDS Behavior, 16, 751-760. doi:10.1007/s10461-011-9953-7

Benotsch, E. G., Kalichman, S., \& Cage, M. (2002). Men who have met sex partners via the internet: Prevalence, predictors, and implications for HIV prevention. Archives of Sexual Behavior, 31, 177-183.

Bowleg, L., Teti, M., Massie, J. S., Patel, A., Malebranche, D. J., \& Tschann, J. M. (2011). "What does it take to be a man? What is a real man?" Ideologies of masculinity and HIV sexual risk among black heterosexual men. Culture, Health \& Sexuality, 13, 545-559. doi:10.1080/13691058.2011.556201

Brooks, R. A., Lee, S., Newman, P. A., \& Leibowitz, A. A. (2008). Sexual risk behavior has decreased among men who have sex with men in Los Angeles but remains greater than that among heterosexual men and women. AIDS Education and Prevention, 20, 312-324. doi:10.1521/aeap.2008.20.4.312

Brown, W. J. (1991). An AIDS prevention campaign: Effects on attitudes, beliefs, and communication behavior. American Behavioral Scientist, 34, 667-678.

Brown, W. J., \& Bocarnea, M. C. (1998). Assessing AIDS-related concern, beliefs, and communication behavior. In C. M. Davis \& W. L. Yarber (Eds.), Handbook of sexuality-related measures (pp. 310-311). Thousand Oaks, CA: Sage.

Centers for Disease Control and Prevention (CDC). (2015a). HIV surveillance report, 25. Retrieved from https://www.cdc.gov/hiv/pdf/library/reports/surveillance/cdc-hiv-surveillance-report2013-vol-25.pdf

Centers for Disease Control and Prevention (CDC). (2015b). HIV surveillance report, 26. Retrieved from https://www.cdc.gov/hiv/pdf/library/reports/surveillance/cdc-hiv-surveillance-reportus.pdf

Centers for Disease Control and Prevention (CDC). (2016a). HIV among people 50 and over. Retrieved from https://www.cdc.gov/hiv/group/age/olderamericans/index.html

Centers for Disease Control and Prevention (CDC). (2016b). HIV surveillance report, 27. Retrieved from https://www.cdc.gov/hiv/pdf/library/reports/surveillance/cdc-hiv-surveillance-report2015-vol-27.pdf

Cooperman, N. A., Arnsten, J. H., \& Klein, R. S. (2007). Current sexual activity and risky sexual behavior in older men with or at risk for HIV infection. AIDS Education and Prevention, 19, 321-333. doi:10.1521/aeap.2007.19.4.321

Davis, C., Hughes, L., Sloan, M., Tang, C., \& MacMaster, S. (2009). HIV/AIDS knowledge, sexual activity, and safer sex practices among female students in Hong Kong, Australia, and the United States. Journal of HIV/AIDS \& Social Services, 8, 414-429. doi:10.1080/15381500903455950

Ebrahim, S. H., Anderson, J. E., Weidle, P., \& Purcell, D. W. (2004). Race/ethnic disparities in HIV testing and knowledge about treatment for HIV/AIDS: United States, 2001. AIDS Patient Care and STDs, 18, 27-33. doi:10.1089/108729104322740893 
Goodenow, C., Szalacha, L. A., Robin, L. E., \& Westheimer, K. (2008). Dimensions of sexual orientation and HIV-related risk among adolescent females: Evidence from a statewide survey. American Journal of Public Health, 98, 1051-1058. doi:10.2105/AJPH.2005.080531

Harris, C. R., Jenkins, M., \& Glaser, D. (2006). Gender differences in risk assessment: Why do women take fewer risks than men? Judgment and Decision Making, 1, 48-63.

Higgins, J. A., \& Wang, Y. (2015). The role of young adults' pleasure attitudes in shaping condom use. American Journal of Public Health, 105, 1329-1332. doi:10.2105/AJPH.2015.302567

Hines, G. (1995). Let's talk about sex. Health Education, 95, 9-12. doi:10.1108/09654289510147414

Kiene, S. M., Fisher, W. A., Shuper, P. A., Cornman, D. H., Christie, S., MacDonald, S., . . Fisher, J. D. (2013). Understanding HIV transmission risk behavior among HIV-infected South Africans receiving antiretroviral therapy: An information-motivation-behavioral skills model analysis. Health Psychology, 32, 860-868. doi:10.1037/a0030554

Kirby, D. B., Laris, B. A., \& Rolleri, L. A. (2007). Sex and HIV education programs: Their impact on sexual behaviors of young people throughout the world. Journal of Adolescent Health, 40, 206-217. doi:10.1016/j.jadohealth.2006.11.143

Klein, H., \& Kaplan, R. L. (2012). Condom use attitudes and HIV risk among American MSM seeking partners for unprotected sex via the Internet. International Public Health Journal, 4, 419-433.

Lefkowitz, E. S., Shearer, C. L., Gillen, M. M., \& Espinosa-Hernandez, G. (2014). How gendered attitudes relate to women's and men's sexual behaviors and beliefs. Sex Culture, 18, 833-846. doi:10.1007/s12119-014-9225-6

Li, X., Lin, C., Gao, Z., Stanton, B., Fang, X., Yin, Q., \& Wu, Y. (2004). HIV/AIDS knowledge and the implications for health promotion programs among Chinese college students: Geographic, gender and age differences. Health Promotion International, 19, 345-356.

doi:10.1093/heapro/dah30

Linley, L., Prejean, J., An, Q., Chen, M., \& Hall, H. I. (2012). Racial/ethnic disparities in HIV diagnoses among persons aged 50 years and older in 37 U.S. states, 2005-2008. American Journal of Public Health, 102, 1527-1534. doi:10.2105/AJPH.2011.300431

Mahat, G., Scoloveno, M. A., \& Scoloveno, R. (2016). HIV/AIDS knowledge, self-efficacy for limiting sexual risk behavior and parental monitoring. Journal of Pediatric Nursing, 31, e63-e69. doi:10.1016/j.pedn.2015.06.015

Maksut, J. L., Eaton, L. A., Siembida, E. J., Driffin, D. D., \& Baldwin, R. (2016). An evaluation of factors associated with sexual risk taking among Black men who have sex with men: A comparison of younger and older populations. Journal of Behavioral Medicine 39, 665-674. doi:10.1007/s10865-016-9734-x

Milligan, C., Cuneo, C. N., Rutstein, S. E., \& Hicks, C. (2014). "Know your status": Results from a novel, student-run HIV testing initiative on college campuses. AIDS Education and Prevention, 26, 317-327. doi:10.1521/aeap.2014.26.4.317

Montaner, J. S. G., Lima, V. D. Harrigan, R., Lourenco, L., Yip, B., Nosyk, B., . . Kendall, P. (2014, February 12). Expansion of HAART coverage is associated with sustained decreases in HIV/AIDS morbidity, mortality and HIV transmission: The "HIV treatment as prevention" experience in a Canadian setting. PLoS ONE, 9, e87872. doi:10.1371/journal.pone.0087872

Moore, S., \& Halford, A. P., (1999). Beliefs and attitudes among male and female adult heterosexuals across four relationship groups. Journal of Health Psychology, 4, 149-163. 
Moore, J., Warren, D., Zierler, S., Schuman, P., Solomon, L., Schoenbaum, E. E., \& Kennedy, M. (1996). Characteristics of HIV-infected lesbians and bisexual women in four urban centers. Women's Health, 2, 49-60.

Pflieger, J. C., Cook, E. C., Niccolai, L. M., \& Connell, C. M. (2013). Racial/ethnic differences in patterns of sexual risk behavior and rates of sexually transmitted infections among female young adults. American Journal of Public Health, 103, 903-909.

doi:10.2105/AJPH.2012.301005

Pleak, R. R., \& Meyer-Bahlburg, H. F. (1990). Sexual behavior and AIDS knowledge of young male prostitutes in Manhattan. Journal of Sex Research, 27, 557-587. doi:10.1080/00224499009551580

Prejean, J., Song, R., Hernandez, A., Ziebell, R., Green, T., Walker, F., . . Hall, I. (2011). Estimated HIV incidence in the United States, 2006-2009. PLoS ONE, 6, e17502. doi:10.1371/journal.pone.0017502

Roehr, B. (2009, November 18). Researchers try to solve the mystery of HIV carriers who don't contract AIDS. Scientific American. Retrieved from http://www.scientificamerican.com/article/hiv-aids-controllers/

Ronis, D. L., Yates, J. F., \& Kirscht, J. P. (1989). Attitudes, decisions, and habits as determinants of repeated behavior. In A. R. Pratkanis \& S. J. Breckler (Eds.), Attitude structure and function (pp. 213-239). Hillsdale, NJ: Lawrence Erlbaum Associates.

Saewyc, E., Skay, C., Richens, K., Reis, R., Poon, C., \& Murphy, A., (2006). Sexual orientation, sexual abuse, and HIV-risk behaviors among adolescents in the Pacific Northwest. American Journal of Public Health, 96, 1104-1110. doi:10.2105/AJPH.2005.065870

Schaalma, H. P., Abraham, C., Gillmore, M. R., \& Kok, G. (2004). Sex education as health promotion: What does it take? Archives of Sexual Behavior, 33, 259-269. doi:10.1023/B:ASEB.0000026625.65171.1d

Sharma, A., Sullivan, S. P., \& Stephenson, R. B. (2017). Detailed knowledge about HIV epidemiology and transmission dynamics and their associations with preventive and risk behaviors among gay, bisexual, and other men who have sex with men in the United States. JMIR Public Health and Surveillance, 3, e11. doi:10.2196/publichealth.7255

Shiferaw, Y., Alemu, A., Assefa, A., Tesfaye, B., Gibermedhin, E., \& Amare, M. (2014). Perception of risk of HIV and sexual risk behaviors among university students: Implication for planning interventions. BMC Research Notes, 7, 162. doi:10.1186/1756-0500-7-162

Slack, C. (2009, July 7). Why do some with HIV not get AIDS? Study of "elite" group may help others. The Washington Post. Retrieved from http://www.washingtonpost.com/wpdyn/content/article/2009/07/06/AR2009070602917.html

Swenson, R. R., Rizzo, C. J., Brown, L. K., Vanable, P. A., Carey, M. P. Valois, R. F., . . Romer, D. (2010). HIV knowledge and its contribution to sexual health behaviors of low-income African American adolescents. Journal of the National Medical Association, 102, 1173-1182.

Tabachnick, B. G., \& Fidell, L. S. (2001). Using multivariate statistics (4th ed.). Boston, MA: Allyn and Bacon.

Turchik, J. A., \& Garske, J. P. (2009). Measurement of sexual risk taking among college students. Archives of Sexual Behavior, 38, 936-948. doi:10.1007/s10508-008-9388-z 
Watson, S. (2012, December 26). AIDS remains dangerous, but not always fatal. Press of Atlantic City. Retrieved from http://www.pressofatlanticcity.com/news/breaking/aids-remainsdangerous-but-not-always-fatal/article_8097ca96-4f1c-11e2-969d-001a4bcf887a.html

Widman, L., Noar, S. M., Choukas-Bradley, S., \& Francis, D. B. (2014). Adolescent sexual health communication and condom use: A meta-analysis. Health Psychology, 33, 1113-1124. doi:10.1037/hea0000112

Wilkinson, D., Tholandi, M., Ramjee, G., \& Rutherford, G. W. (2002). Nonoxynol-9 spermicide for prevention of vaginally acquired HIV and other sexually transmitted infections: Systematic review and meta-analysis of randomized controlled trials including more than 5,000 women. The Lancet Infectious Diseases, 2, 613-617. doi:10.1016/S1473-3099(02)00396-1

World Health Organization (WHO). (2003). Integrating gender into HIV/AIDS Programmes: A review paper. Retrieved from http://apps.who.int/iris/bitstream/10665/42599/1/9241590394.pdf

Ybarra, M. L., Prescott, T. L., Phillips, G. L., Parsons, J. T., Bull, S. S., \& Mustanski, B. (2016). Ethical considerations in recruiting online and implementing a text messaging-based HIV prevention program with gay, bisexual, and queer adolescent males. Journal of Adolescent Health, 59, 44-49. doi:10.1016/j.jadohealth.2016.03.020

Young, S. (2013, December 1). HIV no longer considered death sentence. CNN. Retrieved from http://www.cnn.com/2013/12/01/health/hiv-today/

The Journal of Social, Behavioral, and Health Sciences is an open-access, peer-reviewed, online interdisciplinary journal focusing on research findings that address contemporary national and international issues. Its objectives are to (a) encourage dialogue between scholars and practitioners in the social, behavioral, and health sciences that fosters the integration of research with practice; (b) promote innovative models of interdisciplinary collaboration among the social, behavioral, and health sciences that address complex social problems; and (c) inform the relationship between practice and research in the social, behavioral, and health sciences.

Walden University Publishing: http://www.publishing.waldenu.edu 